\title{
ĐÁNH GIÁ KẾT QUẢ VÀ MộT SỐ YẾU TỐ ẢNH HƯởNG ĐẾN ĐÁP ỨNG CỦA ERLOTINIB TRONG ĐIỀU TRI BƯớC MộT UNG THƯ PHỔI KHÔNG TẾ BÀO NHỎ GIAI ĐOẠN IV CÓ ĐộT BIẾN EGFR
}

\section{TÓM TẮT}

Mục tiêu: Đánh giá hiệu quả và một số yếu tố ảnh hưởng đến đáp ứng của erlotinib trong điều trị bước một ung thư phổi không tế bào nhỏ giai đoạn IV có đột biến gen EGFR. Đối tượng và phương pháp: Nghiên cứu hồi cứu kết hợp tiến cứu trên 131 bệnh nhân ung thư phổi không tế bào nhỏ giai đoạn IV có đột biến EGFR điều trị bằng kháng tyrosine kinase là erlotinib $150 \mathrm{mg} / \mathrm{ngày}$ đến khi bệnh tiến triển. Kết quả: Tỷ lệ đáp ứng hoàn toàn là $0,8 \%$, đáp ứng một phần là $65,6 \%$, tỷ lệ kiểm soát bệnh là $80,9 \%$, chưa phát hiện mối quan hệ giữa tỷ lệ đáp ứng và các yếu tố ảnh hưởng lên quá trình điêuu trị. Kết luận: điều trị erlotinib trong ung thư phổi giai đoạn IV có đột biến EGFR đem lại hiệu quả tốt.

Từ khoá: ung thư phổi không phải tế bào nhỏ, EGFR, ức chế tyrosin kinase

\section{SUMMARY \\ ASSESSMENT OF RESULTS AND SOME FACTORS AFFECTING IN FIRST LINEERLOTINIB TREATMENT OF NON SMALL CEL LUNG CANCER STAGE IV WITH EGFR MUTATION \\ Objective: To evaluate the efficacy and some factors influencing on erlotinib treatment in the primary treatment of stage IV non-small cell lung cancer with EGFR gene mutation. Subjects and methods: A retrospective combined prospective study on 131 stage IV non-small cell lung cancer patients. Results: Complete response was 0,8\%, partial response was $65,6 \%$, disease control rate was $80,9 \%$, no relationship was found between response rates and related factors. Conclusion: Erlotinib treatment in stage IV lung cancer with EGFR mutation is effective.}

Key words: Non-small cell lung cancer, EGFR, tyrosin kinase inhibitor

\section{I. ĐĂT VẤN ĐỀ}

Ung thư phổi là một trong những bệnh ung thư có tỷ lệ mắc mới và tỷ lệ tử vong cao nhất trên thế giới [1]. Mặc dù các phương pháp điều trị ngày càng phát triển nhưng tỷ lệ tử vong do ung thư vẫn rất cao, ngay cả ở những nước phát triển. Việc điều trị ung thư phổi không tế bào nhỏ giai đoạn IV trong nhiêuu năm trước đây dựa

*Bênh viên $K$

Chịu trách nhiệm chính: Phùng Thị Huyên

Email: phungthihuyen@gmail.com

Ngày nhận bài: 5.01.2021

Ngày phản biên khoa hoc: 10.3.2021

Ngày duyệt bài: 18.3.2021
Phùng Thị Huyền*

trên nền tảng cơ bản là hóa trị liệu toàn thân. Những năm gần đây, với những tiến bộ mới trong nghiên cứu con đường dẫn truyền tín hiệu tế bào cũng như các đích phân tử nhất là các tác nhân ức chế Tyrosin kinase tác động lên yếu tố phát triển biểu bì EGFR (Epidermal Growth Factor Receptor) đã làm thay đổi đáng kể tiên lượng và thời gian sống bệnh không tiến triển của những bệnh nhân ung thư phổi giai đoạn muộn [2], [3]. Erlotinib là một trong những thuốc TKIs được chấp thuận trong điều trị ung thư phổi không phải tế bào nhỏ giai đoạn di căn, và đã được chứng minh qua một số nghiên cứu thử nghiệm.ở châu Á, các nghiên cứu cho thây tỷ lệ đột biến EGFR lên tới gần $50 \%$, do vậy chúng tôi tiến hành nghiên cứu này nhằm đánh giá hiệu quả điều trị và tìm hiểu các yếu tố ảnh hưởng đến đáp ứng của thuốc.

\section{II. ĐỐl TƯỢNG VÀ PHƯƠNG PHÁP NGHIÊN CỨU}

Các bệnh nhân UTPKTBN có đột biến EGFR, điều trị bước một bằng Erlotinib tại bệnh viện Đại học Y Hà Nội và bệnh viện $K$ từ 06/2015 đến 03/2020.

2.1 Tiêu chuẩn lựa chọn bệnh nhân. Bệnh nhân được chẩn đoán UTPKTBN loại ung thư biểu mô tuyến, giai đoạn IV(AJCC 2017); Có đột biến EGFR tại exon 19 (Del19) hoặc exon 21 (L858R); Được điều trị bước một bằng Erlotinib $150 \mathrm{mg}$, uống 01 viên/ngày trong thời gian ít nhất 02 tháng tính đến thời điểm kết thúc nghiên cứu; Đánh giá chỉ số toàn trạng trước điêu trị (ECOG): 0, 1, 2, 3; Tuổi $\geq 18$.

2.2 Tiêu chuẩn loại trừ. Không đáp ứng một trong các tiêu chuẩn lựa chọn; Có ung thư khác phối hợp đã được chẩn đoán xác định.

2.3 Thiểt kế nghiên cứu. Là nghiên cứu mô tả hồi cứu kết hợp tiến cứu. Chọn mẫu thuận tiện.

\section{KẾT QUẢ NGHIÊN CỨU}

\subsection{Kết quả đáp ứng}

Bảng 1.Thời gian sử dụng thuốc

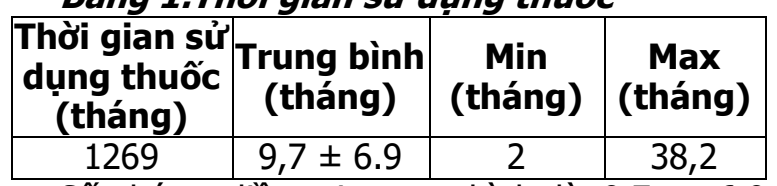

Số tháng điêu trị trung bình là $9,7 \pm 6,9$ tháng. Ngắn nhất là 2 tháng, dài nhất là 38,2 tháng. 


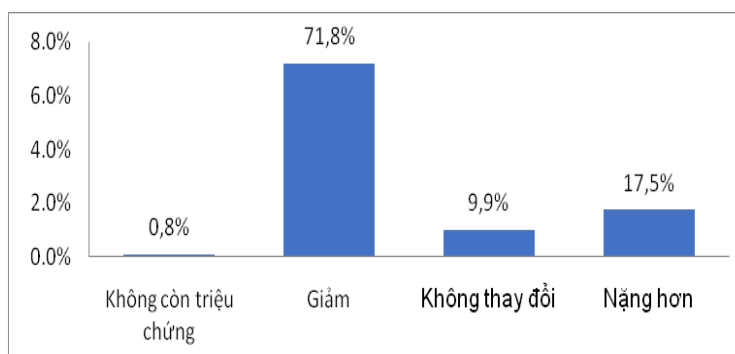

Biểu đồ 1: Tỷ lê đáp ứng cơ năng

Phần lớn $\mathrm{BN}$ có triệu chứng thuyên giảm sau điều trị $(71,8 \%)$. Có $9,9 \%$ số BN không cải thiện và $17,5 \%$ cảm thây tình trạng nặng lên.
Bảng 2. Tỷ lệ bệnh nhân theo mức độ đáp ứng khách quan

\begin{tabular}{|c|c|c|}
\hline Đáp ứng & $\begin{array}{c}\text { Số bệnh } \\
\text { nhân }(\mathbf{n})\end{array}$ & $\begin{array}{c}\text { Tỷ lệ } \\
\mathbf{( \% )}\end{array}$ \\
\hline Đáp ứng hoàn toàn & 1 & 0,8 \\
\hline Đáp ứng một phần & 86 & 65,6 \\
\hline Bệnh giữ nguyên & 19 & 14,5 \\
\hline Bệnh tiến triến & 25 & 19,1 \\
\hline Tống & 131 & 100 \\
\hline
\end{tabular}

Phần lớn các BN đat được đáp ứng môt phần sau điều trị, chiếm tỷ lệ $65,6 \%$. Có 1 trường hợp đạt đáp ứng hoàn toàn (chiếm 0,8\%). Có 19,1\% BN tiến triển.

\section{Bảng 3. Sống thêm không tiến triển}

\begin{tabular}{|c|c|c|c|c|c|}
\hline \multicolumn{7}{|c|}{ Sống thêm không tiến triến } \\
\hline Trung vị(tháng) & Min(tháng) & Max(tháng) & $\mathbf{3}$ tháng(\%) & $\mathbf{6}$ tháng(\%) & $\mathbf{1 2}$ tháng(\%) \\
\hline 11,8 & 2,0 & 38,2 & 91,5 & 75,1 & 48,5 \\
\hline
\end{tabular}

Thời gian sống thêm không tiến triển trung vị là 11,8 tháng, ngắn nhất là 2 tháng, dài nhất là 38,2 tháng. STKTT 3 tháng đạt 91,5\%; 12 tháng: $48,1 \%$

\section{Bảng 4. Thời gian sống thêm toàn bố}

\begin{tabular}{|c|c|c|c|c|c|}
\hline \multicolumn{7}{|c|}{ Sống thêm toàn bộ } \\
\hline Trung vị (tháng) & Min(tháng) & Max(tháng) & $\mathbf{6}$ tháng(\%) & $\mathbf{1}$ năm(\%) & $\mathbf{2}$ năm(\%) \\
\hline 20,9 & 2,0 & 38,8 & 88,1 & 75,3 & 44,3 \\
\hline
\end{tabular}

Thời gian sống thêm toàn bô trung vi đat 20,9 tháng, ngắn nhất là 2 tháng, dài nhất là 38,8 tháng. Tại thời điểm 12 tháng, tỷ lệ sống thêm toàn bộ đạt 75,3\%.

3.2. Đánh giá đáp ứng và một số yếu tố liên quan

\section{Bảng 5. Sống thêm không tiến triển theo tuổi}

\begin{tabular}{|c|c|c|c|c|c|c|c|}
\hline \multirow[b]{2}{*}{ Tuổi } & \multicolumn{6}{|c|}{ Sống thêm không tiến triến } & \multirow[b]{2}{*}{ p } \\
\hline & $\begin{array}{l}\text { Trung vi! } \\
\text { (tháng) }\end{array}$ & $\begin{array}{c}\text { Min } \\
\text { (tháng) }\end{array}$ & $\begin{array}{c}\text { Max } \\
\text { (tháng) }\end{array}$ & $\begin{array}{c}3 \text { tháng } \\
(\%)\end{array}$ & $\begin{array}{c}6 \text { tháng } \\
(\%)\end{array}$ & $\begin{array}{c}1 \text { năm } \\
\text { (\%) }\end{array}$ & \\
\hline$\leq 6$ & 10,8 & 2 & 24,6 & 90,4 & 75,7 & 42 & \\
\hline$>60$ tuối $(n=58)$ & 14,7 & 2 & 38,2 & 92,9 & 74,4 & 55,7 & 0,087 \\
\hline
\end{tabular}

ơ nhóm tuối trên 60 tuối, trung vị STKTT là 14,7 tháng cao hơn so với nhóm $\leq 60$ tuối là 10,8 tháng, tuy nhiên sự khác biệt là khồng có ý nghĩa thống kê với $p>0,05$.

Bảng 6. Sống thêm không tiến triên theo giới

\begin{tabular}{|c|c|c|c|c|c|c|c|}
\hline \multirow[b]{2}{*}{ Giới } & \multicolumn{6}{|c|}{ Sống thềm không tiến triến } & \multirow[b]{2}{*}{ p } \\
\hline & $\begin{array}{l}\text { Trung vị } \\
\text { (tháng) }\end{array}$ & $\begin{array}{c}\text { Min } \\
\text { (tháng) }\end{array}$ & $\begin{array}{c}\text { Max } \\
\text { (tháng) }\end{array}$ & $\begin{array}{c}3 \text { tháng } \\
(\%)\end{array}$ & $\begin{array}{c}6 \text { tháng } \\
(\%)\end{array}$ & $\begin{array}{c}1 \text { năm } \\
(\%)\end{array}$ & \\
\hline Nam ( & 12,7 & 2 & 31,1 & 93,1 & 74,1 & 51,4 & \\
\hline$N \tilde{u}(n=5$ & 10,8 & 2 & 38,2 & 89,5 & 76,4 & 44,6 & 0,379 \\
\hline
\end{tabular}

Trung vị thời gian STKTT ở nam cao hơn so với nữ giới, lần lượt là 12,7 tháng và 10,8 tháng, tuy nhiên sự khác biệt không có ý nghĩa thống kê với p > 0,05.

Bảng 7. Thời gian sống thêm không tiến triên theo đột biến EGFR

\begin{tabular}{|c|c|c|c|c|c|c|c|}
\hline \multirow{2}{*}{$\begin{array}{c}\text { Loại } \\
\text { đột biến }\end{array}$} & $\begin{array}{c}\text { Srung vị } \\
\text { (tháng) }\end{array}$ & $\begin{array}{c}\text { Min } \\
\text { (tháng) }\end{array}$ & $\begin{array}{c}\text { Max } \\
\text { (tháng) }\end{array}$ & $\begin{array}{c}\mathbf{3} \text { tháng } \\
\mathbf{( \% )}\end{array}$ & $\begin{array}{c}\mathbf{6} \text { tháng } \\
\mathbf{( \% )}\end{array}$ & $\begin{array}{c}\mathbf{1} \text { năm } \\
\mathbf{( \% )}\end{array}$ & \multirow{2}{*}{$\mathbf{p}$} \\
\hline Exon 19 $(\mathrm{n}=74)$ & 11,7 & 2 & 31,3 & 94,5 & 74,5 & 47 & \\
\hline Exon $21(\mathrm{n}=57)$ & 12,7 & 2 & 38,2 & 87,5 & 76 & 50,3 & 0,771 \\
\hline
\end{tabular}

Nhận xét: Trung vị STKTT ở BN có đột biến exon 19 và exon 21 lần lượt là 11,7 tháng và 12,7 tháng. Sự khác biệt không có ý nghĩa thống kê với $p>0,05$.

Bảng 8. Thời gian sống thêm toàn bộ theo đột biến EGFR

\begin{tabular}{|c|c|c|c|c|c|c|c|}
\hline \multirow{2}{*}{$\begin{array}{c}\text { Loại } \\
\text { đột biến }\end{array}$} & $\begin{array}{c}\text { Sống thêm toàn bộ } \\
\text { (thúng vị }\end{array}$ & $\begin{array}{c}\text { Min } \\
\text { (tháng) }\end{array}$ & $\begin{array}{c}\text { Max } \\
\text { (tháng) }\end{array}$ & $\begin{array}{c}\mathbf{6} \text { tháng } \\
(\%)\end{array}$ & $\begin{array}{c}\mathbf{1} \text { năm } \\
(\%)\end{array}$ & $\begin{array}{c}\mathbf{2} \text { năm } \\
(\%)\end{array}$ & $\mathbf{p}$ \\
\hline
\end{tabular}




\begin{tabular}{|l|l|l|l|l|l|l|l|} 
Exon $19(\mathrm{n}=74)$ & 23,3 & 2 & 33,1 & 87,4 & 79,9 & 49,6 & \\
\hline Exon $21(\mathrm{n}=57)$ & 17,8 & 3,0 & 38,8 & 88,9 & 70,6 & 38,8 & 0,241 \\
\hline
\end{tabular}

Nhận xét: Trung vị thời gian sống thêm của nhóm có đột biến exon 19 cao hơn so với nhóm đột biến exon 21 , tương ứng là 23,3 và 17,8 tháng. Tai thời điểm 1 năm và 2 năm, tỷ lê sống thêm của nhóm có đột biến exon 19 cũng cao hơn tương ứng là 79,9\% và 49,6\% so với nhóm có đột biến exon 21 lần lượt là $70,6 \%$ và 38,8\%. Tuy nhiên, sự khác biệt này là không có ý nghĩa thống kê, với $p>0,05$.

\section{BÀN LUÂNN}

Tổng số tháng sử dụng thuốc là 1269 tháng. Thời gian điều trị trung bình là $9,7 \pm 6,9$ tháng, ngắn nhất là 2 tháng, dài nhất là 38,2 tháng. Trong 33 BN có di căn não, có 22 BN được xạ trị toàn não hoặc gamma knife, chiếm tỷ lệ $66,7 \%$, những $B N$ di căn não đơn ổ, thể tích nhỏ, diện tích phù não xung quanh bé, không có triệu chứng lâm sàng được theo dôi trong quá trình điêu trị. Đây là điểm khác biệt của nghiên cứu chúng tôi so với một số nghiên cứu khác là tiến hành xạ trị đối với tất cả các trường hợp có di căn não. Các trường hợp có di căn xương được sử dụng thuốc biphosphonat mối $1-3$ tháng, một số trường hợp được xạ trị giảm đau xương. Ngoài ra, một số $B N$ có tràn dịch màng phổi số lượng nhiều, ảnh hưởng đến cơ năng của $\mathrm{BN}$ được tiến hành chọc tháo dịch màng phổi, đánh giá khoảng thời gian giữa 2 lần phải chọc dịch.

Trong nghiên cứu này chúng tôi đánh giá đáp ứng chủ quan dựa trên sự thay đổi các triệu chứng cơ năng của bệnh nhân như ho, đau ngực, khó thở. Kết quả cho thấy, phần lớn $B N$ có triệu chứng thuyên giảm sau điều trị (chiếm $71,8 \%$ ). Có $9,9 \%$ số $B N$ không cải thiện và $17,5 \%$ số BN cảm thấy tình trạng nặng lên. Điều này có nghĩa là đa phần $B N$ nhận được lợi ích từ việc điều trị, cải thiện triệu chứng từ đó cải thiện chất lượng cuộc sống - là một mục tiêu quan trọng trong điểu trị ung thư giai đoạn muộn nói chung và ung thư phổi nói riêng.

Đánh giá tỷ lệ đáp ứng và tỷ lệ kiểm soát bệnh dựa trên tiêu chuẩn RECIST. Phần lớn các BN đạt được đáp ứng một phần sau điều trị, chiếm tỷ ệ $65,6 \%$. Có một trường hợp đạt đáp ứng hoàn toàn (chiếm $0,8 \%$ ) và có $19,1 \% \mathrm{BN}$ tiến triển. Tỷ lệ kiểm soát bệnh (đáp ứng hoàn toàn, đáp ứng một phần, bệnh giữ nguyên) đạt $80,9 \%$. Kết quả này tương tự với nhiêu nghiển cứu khác trong nước và trển thể giới. Trong nghiên cứu OPTIMAL trên nhóm đối tượng là BN châu Á (Trung Quốc), ở nhóm điều trị bằng erlotinib, tỷ lệ đáp ứng hoàn toàn là $2 \%$, đáp ứng môt phần là $80 \%$ và tỷ lê kiểm soát bênh lên tới 96\%. Nghiên cứu JO22903 ở BN Nhật Bản, tỷ lệ đáp ứng (đáp ứng hoàn toàn, đáp ứng một phân) được báo cáo là $78 \%$, tỷ lệ kiểm soát bênh là $95 \%$. Theo nghiên cứu EURTAC trên nhóm BN châu Âu, tỷ lệ đáp ứng hoàn toàn là $3 \%$, đáp ứng một phần là $61 \%$. Nhìn chung, trong các nghiên cứu về điều trị erlotinib bước một trong UTPKTBN giai đoạn IV đều thu được tỷ lệ đáp ứng và tỷ lệ kiểm soát bệnh cao [4],[5].

Mục tiêu điều trị ung thư phổi giai đoạn muộn là cải thiện triệu chứng, nâng cao chất lượng cuộc sống, kéo dài thời gian sống thêm không tiến triển cũng như thời gian sống thêm toàn bộ cho người bệnh. Theo các nghiên cứu đã được báo cáo,mặc dù tỷ lệ đáp ứng cao song trung vị thời gian sống thêm của nhóm điều trị bằng erlotinib chỉ đạt từ $8,4-13,1$ tháng [6],[7]. Trong nghiên cứu của chúng tối, thời gian sống thêm không tiến triển trung vị là 11,8 tháng, ngắn nhất là 2 tháng, dài nhất là 38,2 tháng. Trong kết quả nghiên cứu của chúng tôi, thời gian sống thêm toàn bộ trung vị là 20,9 tháng, thấp nhất 2 tháng, dài nhất là 38,8 tháng. Tại thời điểm 12 tháng, tỷ lệ sống thêm toàn bộ đạt $75,3 \%$, tại thời điểm 2 năm là $44,3 \%$.

Qua phân tích mối tương quan giữa thời gian sống thêm không tiến triển và một số yếu tố chúng tôi nhận thấy sự khác biệt giữa các nhóm là không có ý nghĩa thống kê, với giá trị $p>0,05$.

Khi phân tích sự tương quan giữa sống thêm toàn bộ và các yểu tố tiền sử hút thuốc, tình trang đột biến gen EGFR, di căn não cho thấy không có mối tương quan giữa các yếu tố trên với thời gian sống thêm toàn bộ, sự khác biệt là không có ý nghĩa thống kê với $p>0,05$, có lẽ đối tượng bệnh nhân vẩn còn khu trú tại hai địa điểm nghiên cứu, chưa đại diện cho quần thể bệnh nhân ung thư phổi giai đoạn di căn ở nước ta, do vậy cần có những nghiên cứu có cõ̃ mẫu lớn hơn để phân tích sâu hơn mối quan hê giữa các yếu tố ảnh hưởng đến đáp ứng để đưa ra tiên lượng bệnh cho bệnh nhân.

\section{KẾT LUẬN}

Điều trị erlotinib trên các bệnh nhân ung thư phổi không tế bào nhỏ giai đoạn IV có đột biến EGFR đem lại hiệu quả tốt, có thể áp dụng cả với những bênh nhẩn có thể trạng không tốt. Hiê̂n tại chưa thấy mối liên quan có ý nghĩa của một số yếu tố ảnh hưởng đến hiệu quả điều trị erlotinib. 


\section{TÀI LIÊU THAM KHẢO}

1. GLOBOCAN. International agency for research on cancer. 2018.

2. Rosell $\mathbf{R}$, Carcereny $E$, Gervais $R$, et al. Erlotinib versus standard chemotherapy as firstline treatment for European patients with advanced EGFR mutation-positive non-small-cell lung cancer (EURTAC): a multicentre, open-label, randomised phase 3 trial. Lancet Oncol. Mar 2012. 13(3):239-246. doi:10.1016/S1470-2045(11)70393-X.

3. Gao G, Ren S, Li A, et al. Epidermal growth factor receptor-tyrosine kinase inhibitor therapy is effective as first-line treatment of advanced nonsmall-cell lung cancer with mutated EGFR: A metaanalysis from six phase III randomized controlled trials. Int J Cancer. Sep 1 2012. 131(5):E822-829. doi:10.1002/ijc.27396.

4. Gridelli C, Rossi A. EURTAC first-line phase III randomized study in advanced non-small cell lung cancer: Erlotinib works also in European population. J Thorac Dis. Apr 1 2012. 4(2):219220. doi:10.3978/j. issn.2072-1439.2012.03.03.

5. Zhou C, Wu YL, Chen G, et al. Final overall survival results from a randomised, phase III study of erlotinib versus chemotherapy as first-line treatment of EGFR mutation-positive advanced non-small-cell lung cancer (OPTIMAL, CTONG0802). Ann Oncol. Sep 2015. 26(9):1877-1883. doi:10.1093/annonc/mdv276.

6. Nguyền Minh Hà, Ta Thành Văn và $C S$. Erlotinib bước môt trên bênh nhân ung thư phổi không tế bào nhỏ giai đoạn muộn có đột biến gen EGFR. Tap chí nghiên cứu y học. 2014 2014.Phụ trương 91, 97-14.

7. Nguyên Thanh Hoa, Lê Văn Quảng, Đỗ Hùng Kiên. Đánh giá kết quả điêuu tri bước môt của thuốc erlotinib trên bệnh nhân ung thư phổi không tế bào nhỏ tai bệnh viện K. 2019 ed2019.

\section{MộT SỐ YẾU TỐ LIÊN QUAN ĐẾN KIẾN THỨC CHĂM SÓC SAU SINH CỦA BÀ ME SINH CON LẦ ĐẦU SINH TẠI BÊ̂NH VIỆN PHỤ SẢN THÁI BÌNH}

TÓM TẮT.

Nghiên cứu thực hiện trên 245 bà mẹ sinh con lần đầu tại Bênh viên Phư Sản Thái Bình. Kết quả cho thây không có mối liên quan giữa tuổi, nghề nghiệp, và nơi sống với kiến thức chăm sóc của bà me với các chi số lần lượt là $(\mathrm{OR}=1,455 ; \mathrm{CI}: 0,717-2,954$; $\mathrm{P}=0,299), \quad(\mathrm{OR}=1,012 ; \quad \mathrm{CI}: 0,784-1,308 ; \mathrm{P}=0,925)$, $(\mathrm{OR}=0,364 ; \mathrm{CI}: 0,106-1,246 ; \mathrm{P}=0,107)$. Về trình độ học vấn các bà me có trình độ học vấn từ trung cấp/ cao đẳng, đại học đạt kiến thức về chăm sóc sau sinh gấp 2,2 lần các bà mẹ có trình độ học vấn từ cấp II trở xuống. Sự khác biệt có ý nghĩa thống kê $(\mathrm{OR}=2,226 ; \mathrm{CI}: 1,395-3,552 ; \mathrm{P}=0,001)$.

Từ khóa: yếu tố liên quan sau sinh, chăm sóc sau sinh, trẻ sơ sinh

\section{SUMMARY \\ FACTORS RELATED TO POSTNATAL CARE \\ KNOWLEDGE OF FIRST-TIME MOTHERS GIVING BIRTH AT THAI BINH OBSTETRICS AND GYNECOLOGY HOSPITAL}

The study was conducted on 245 mothers who gave birth for the first time at Thai Binh Maternity Hospital. The results showed that there was no correlation between age, occupation, and place of residence with postnatal care knowledge of mothers and the indicators are $(\mathrm{OR}=1.455 ; \mathrm{CI}: 0.717-2.954$;

*Trương Đại học Y Dược Thái Bình

Chịu trách nhiệm chính: Bùi Minh Tiến

Email: Tienbm@tbmc.edu.vn

Ngày nhận bài: 5.01.2021

Ngày phản biện khoa học: 5.3.2021

Ngày duyệt bài: 15.3.2021
Bùi Minh Tiến*

$\mathrm{P}=0.299),(\mathrm{OR}=1.012 ; \mathrm{CI}: 0.784-1.308 ; \mathrm{P}=$ $0.925),(O R=0.364 ; C I: 0.106-1.246 ; P=0.107)$ respectively. In terms of education, mothers with higher educational level from technical schools/ colleges and universitíe have 2.2 times more postnatal care knowledge than mothers with secondary education or lower education levels. The difference was statistically significant $(\mathrm{OR}=2.226$; CI: $1.395-$ 3.552; $\mathrm{P}=0.001$ ).

Keywords: Postnatal related factors, postnatal care, newborn babies

\section{I. ĐĂT VẤN ĐỀ}

Thời kỳ hậu sản là khoảng thời gian 6 tuần lễ sau sinh. Trong khoảng thời gian này, các cơ quan trong cơ thể người me nhất là những cơ quan sinh dục sẽ dần dần trở về trạng thái bình thường như trước khi có thai. Đa số các bà mẹ sau sinh thường chỉ nằm viện trong thời gian ngắn chỉ từ 1-2 ngày (24-48 giờ đầu tiên), hoạt động chăm sóc trong thời gian này hầu hết phụ thuộc vào nhân viên y tế và người nhà. Ngoài ra, bà mẹ mới sinh thường thiếu kiến thức tự chăm sóc cho bản thân và chăm sóc cho trẻ sơ sinh [9]. Các thăm khám sau sinh kể từ khi xuất viện cho đến hết thời kỳ hậu sản (42 ngày) hiên chưa được quan tâm. Chính vì vậy việc các bà mẹ có kiến thức về chăm sóc hậu sản và sơ sinh là rất quan trong, và quan trong hơn với bà me sinh con lần đầu. Do đó chúng tôi thực hiện đề tài với mục tiêu: "Tìm hiểu một số yếu tố liên quan đến kiến thức chăm sóc sau sinh của bà mẹ" 